\title{
Pre-Med Major and Automaticity Ability
}

\author{
Cynthia Powell and Diana Mason* \\ Department of Chemistry, University of North Texas, USA
}

*Corresponding author: Diana Mason, Professor Emeritus, Department of Chemistry, University of North Texas, USA

\begin{tabular}{ll}
\hline ARTICLE INFO & ABSTRACT \\
\hline
\end{tabular}

Received: 㓞 September 09, 2021

Published: 絊 September 20, 2021
Abbreviations: NSA: Networking for Science Advancement; MUST: Math-Up Skills Test; TEA: Texas Education Agency; QR: Quantitative-Reasoning

Citation: Cynthia Powell, Diana Mason. Pre-Med Major and Automaticity Ability. Biomed J Sci \& Tech Res 38(5)-2021. BJSTR. MS.ID.006216.

\section{Opinion}

The Texas Networking for Science Advancement (NSA) team formed in 2016. The team now consists of 15 faculty from 10 Texas universities. Five of the partnering universities are classified as Hispanic-Serving Institutions (at least 25\% Hispanic enrollment) and the other five are considered as Hispanic-emerging (16$24 \%$ Hispanic enrollment). Two of the 10 institutions are private universities, and the remaining are public. To date, the team has published results of eight studies (two currently in press) evaluating general chemistry students' QR arithmetic automaticity skills (what students can do without a calculator) using the MathUp Skills Test (MUST), a 20-question, 15-min, hand-graded, openended diagnostic instrument [1-3]. One of our carrots to encourage students to try this quiz without using their trusted calculating devices is that the MCAT is a calculator-free evaluation instrument and over $50 \%$ of our general chemistry students indicate an interest to enter the health professions.

\section{The Good}

From the very first observation, the team's results provided a linear trend-the better students' arithmetic skills the better their general chemistry averages in both first- and second-semesters. The results not expected are that there is a stronger relationship between what students can do without a calculator (their automaticity) than what they can do with a calculator. Yes, the students did better on the MUST with a calculator but the effect size without a calculator is stronger. The statistics consistently support that the MUST is highly reliable (KR-20 > .80), has good internal consistency (Cronbach's alpha > .85), and the Cohen's $d$ for the MUST is consistently $>1.0$ indicating a large effect size for a population of over 10,000 students. Using the MUST has provided the team with a diagnostic instrument that allows instructors the ability to identify at-risk students in $15 \mathrm{~min}$ the first week of classes. Being able to identify these students who will struggle with the course material early in the semester provides ample time for corrective measures to be employed in hopes that students will take advantage of the opportunity but herein lies the rub: it's the rich that get richer! Pilot studies indicate that this trend carries onto lower-level organic chemistry courses.

\section{The Bad}

The original study came about because the team noticed that Texas students' SAT scores were consistently declining below the national average. This trend coincided with the Texas Education Agency (TEA) mandated change from a $4 \times 4$ high stakes testing system consisting of a series of four exams per year in four subjects (mathematics, science, social studies and English) during the final four years of secondary school. TEA's current testing-system focuses on only two STEM areas (biology and first-year algebra) along with 
first- and second-year English and US History. The TEA calculator policy states no calculators are permitted on STAARs (State of Texas Assessments of Academic Readiness) in grades 3-7, but districts must ensure that each student has a graphing calculator to use on all STAARs starting with 8th-grade mathematics (both paper and online versions) and biology. For the biology assessment, there should be one calculator (four-function, scientific, or graphing) for every five students. Students may bring their own calculators with them to the assessments, but internet capabilities must be disabled and calculation applications on smartphones are not allowed. Beginning in May 2018, the grade 8 science STAAR requires students to have access to calculators with four-functions, scientific or graphing capability. What is not obvious is how much these rules/ regulations are hurting the students' future preparation for postsecondary success. Handheld calculators are generally accepted for classroom use and allow teachers to give beginning students realistic problems using tangible data gathered from the field. All is good but how many times do students calculate a negative mass or an unrealistic density and not have the quantitative-reasoning ability or basic number sense to know that the "calculator" answer is impossible or improbable.

\section{The Future}

When students enter post-secondary education with low automaticity ability, they lack the mental-math skills needed to succeed in general chemistry, a major gateway course to many STEM-major degrees. Adding more calculator-free instruction for all STEM and non-STEM majors in general chemistry (and other STEM courses) is advisable and will improve students' mental- math capability. Summer bridge programs, weekly recitations and the like should emphasize students' automaticity skills to help prepare incoming students for success. However, quantitativereasoning (QR) skills (like those needed to understand how to read scientific data graphs and charts) are required to understand much of our current data-driven world needed to prepare global citizens for both STEM and non-STEM careers. Improving our students' QR calculator-free skills is a place to start to attempt to improve retention and graduation rates for all students. Is this the answer? Maybe or maybe not, but what is obvious is that we are going in the wrong direction. Without a doubt, students need more quantitative-reasoning and quantitative-literacy skills to have a chance of succeeding in this data-driven world. To encourage students to use their calculator-free skills, teach part of your class without the use of a calculator. Ask students how they arrived at their answers, what is their logic-it might surprise you as to what they can and cannot do without using calculators, and as a result their automaticity abilities and MCAT scores might improve!

\section{References}

1. Williamson VM, Walker DR, Chuu E, Broadway S, Mamiya B, et al. (2020) Impact of basic arithmetic skills on success in first-semester general chemistry. Chemistry Education Research and Practice 21(1): 51-61.

2. Powell CM, Simpson J, Williamson VM, Dubrovskiy A, Walker DR, et al. (2020) Impact of arithmetic automaticity on students' success in second-semester general chemistry. Chemistry Education Research and Practice 21(4): 1028-1041.

3. Weber R, Powell CB, Williamson V, Mamiya B, Walker DR, et al. (2020) Relationship between academic preparation in general chemistry and potential careers. Biomedical Journal of Scientific \& Technical Research 32(5): 25311-25323.
ISSN: 2574-1241

DOI: $10.26717 /$ BJSTR.2021.38.006216

Diana Mason. Biomed J Sci \& Tech Res

(c) (P) This work is licensed under Creative Commons Attribution 4.0 License

Submission Link: https://biomedres.us/submit-manuscript.php

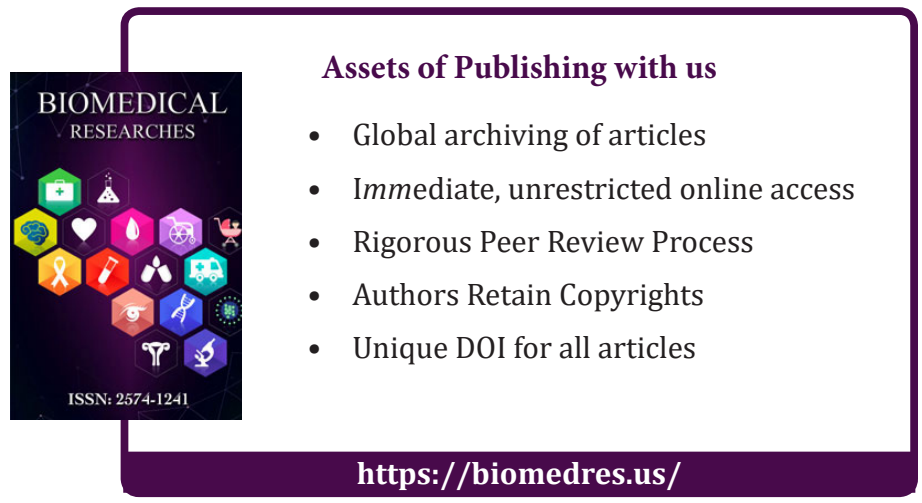

